\title{
Preliminary findings indicate nosocomial transmission and Roma population as most affected group in ongoing measles B3 genotype outbreak in Bulgaria, March to August 2017
}

A Kurchatova ${ }^{1}$, S Krumova ${ }^{1}$, N Vladimirova ${ }^{1}$, L Nikolaeva-Glomb ${ }^{1}$, A Stoyanova ${ }^{1}$, T Kantardjiev ${ }^{1}$, N Gatcheva ${ }^{2}$

1. National Centre of Infectious and Parasitic Diseases, Sofia, Bulgaria

2. Bulgarian Association for Prevention and Infection Control - BulNoso, NGO, Sofia, Bulgaria

Correspondence: Anna Kurchatova (akurchatova@ncipd.org)

Citation style for this article:

Kurchatova A, Krumova S, Vladimirova N, Nikolaeva-Glomb L, Stoyanova A, Kantardjiev T, Gatcheva N. Preliminary findings indicate nosocomial transmission and Roma population as most affected group in ongoing measles B3 genotype outbreak in Bulgaria, March to August 2017. Euro Surveill. 2017;22(36):pii=30611. D0I: http://dx.doi.org/10.2807/1560-7917.ES.2017.22.36.30611

Article submitted on 21 August 2017 / accepted on 07 September 2017 / published on 07 September 2017

From March to August 2017, 165 measles cases were reported from three regions in Bulgaria. The age range was $0-55$ years and $66 \%$ of the cases were under 9 years. The Roma population was disproportionally affected ( $89 \%$ of cases), $41 \%$ cases were unvaccinated and in 24 cases there was nosocomial transmission mostly in paediatric departments. A child under 12 months of age died. Control measures have been taken and the investigation is still ongoing.

\section{Outbreak description}

Since 17 March and until 31 August 2017, a total of 204 suspected measles cases were reported to the webbased National Measles Surveillance System (NMSS) in Bulgaria. In Bulgaria, measles has been a statutorily notifiable disease since 1921 [1]. National case-based notification started in 2004 and in 2005, the European Union (EU) case definition and case classification were adopted for surveillance purposes [2,3]. The NMSS was developed and introduced in 2009 (http://mmr.gateway.bg/en/).

Here we present preliminary findings and the control measures implemented at the beginning of the ongoing measles outbreak.

\section{Case definition and classification}

For the outbreak investigation, the EU measles case definition is being used [2]. Any person meeting the clinical criteria i.e. fever, maculopapular rash and at least one of cough/coryza/conjunctivitis, is classified as possible case; any person meeting the clinical criteria and with an epidemiological link to a laboratoryconfirmed case is classified as a probable case; and any person not vaccinated in the previous 6 weeks and meeting the clinical and the laboratory criteria is defined as a confirmed case.

Thirty-nine cases did not fulfil the case definition and were discarded on the basis of laboratory criteria and epidemiological data [4].The remaining 165 cases were classified according to [2], as follows: 122 confirmed, 36 probable and seven possible cases. All cases were epidemiologically investigated and laboratory tests were performed at the National Reference Laboratory for Measles, Mumps and Rubella (NRL-MMR) at the National Centre of Infectious and Parasitic Diseases (NCIPD) in Sofia. Sera collected in the region of Plovdiv after mid-May were tested for IgM/IgG at the Medical University of Plovdiv.

\section{Epidemiology and case characteristics}

The index case in the outbreak was a 2-year-old child from a large Roma community in Plovdiv. The child was admitted to the infectious diseases ward of the regional hospital with diarrhoea and other enterocolitis symptoms. After 3 days, the child developed typical measles symptoms and the national health authorities were informed on the same day. There was further transmission in the family or in the hospital setting. The epidemic curve of cases by week of symptom onset shows the dynamics of outbreak (Figure 1 ).

Males ( $n=93)$ were more affected than females $(n=72$; ratio: $1: 0.8)$. The majority of cases $(n=107$; $65 \%$ ) were children under 9 years of age. The median age of cases was 4 years (range: $\langle 1-55)$. A high number of cases were not immunised $(n=67,41 \%)$ and nearly half of them $(n=35)$ were children under 1 year of age who are not eligible for vaccination. 


\section{FIgURE 1}

Measles cases by week of symptom onset, Bulgaria, March-August 2017 ( $n=165)$

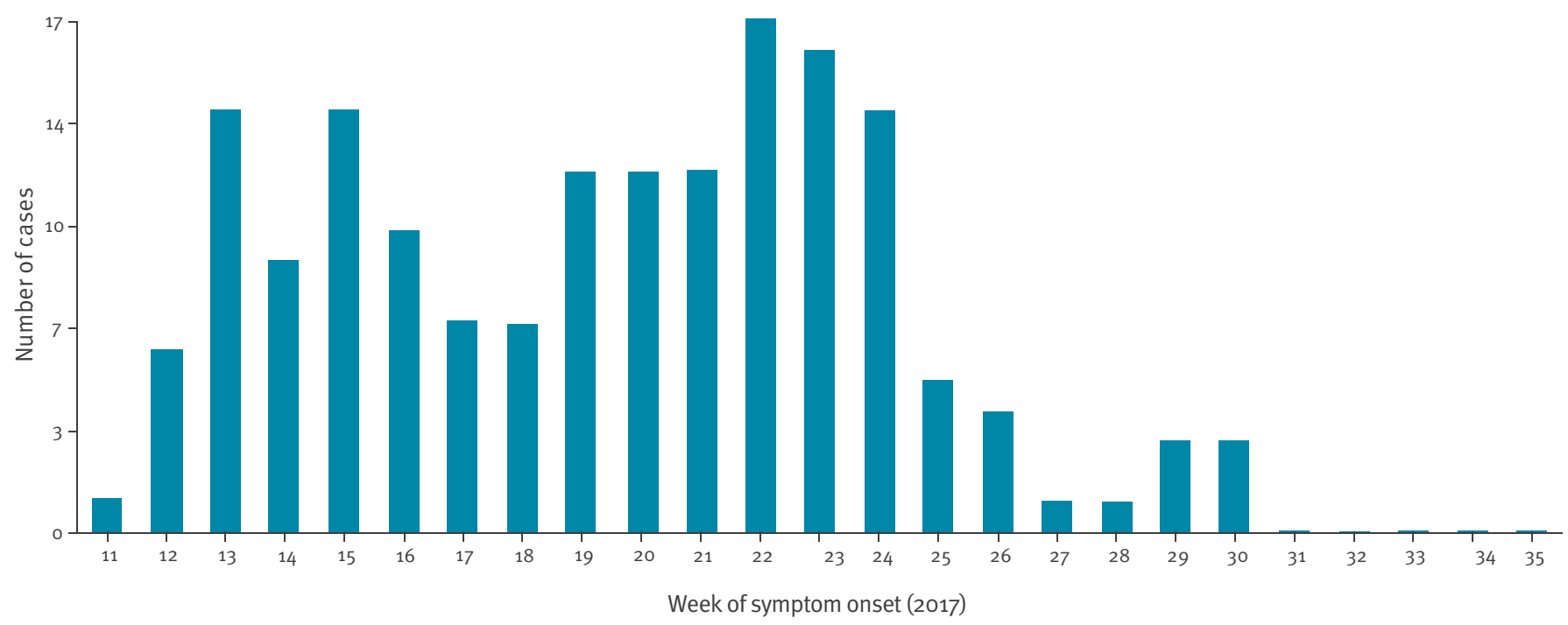

FIGURE 2

Measles cases by region, Bulgaria, March-August $2017(\mathrm{n}=165)$

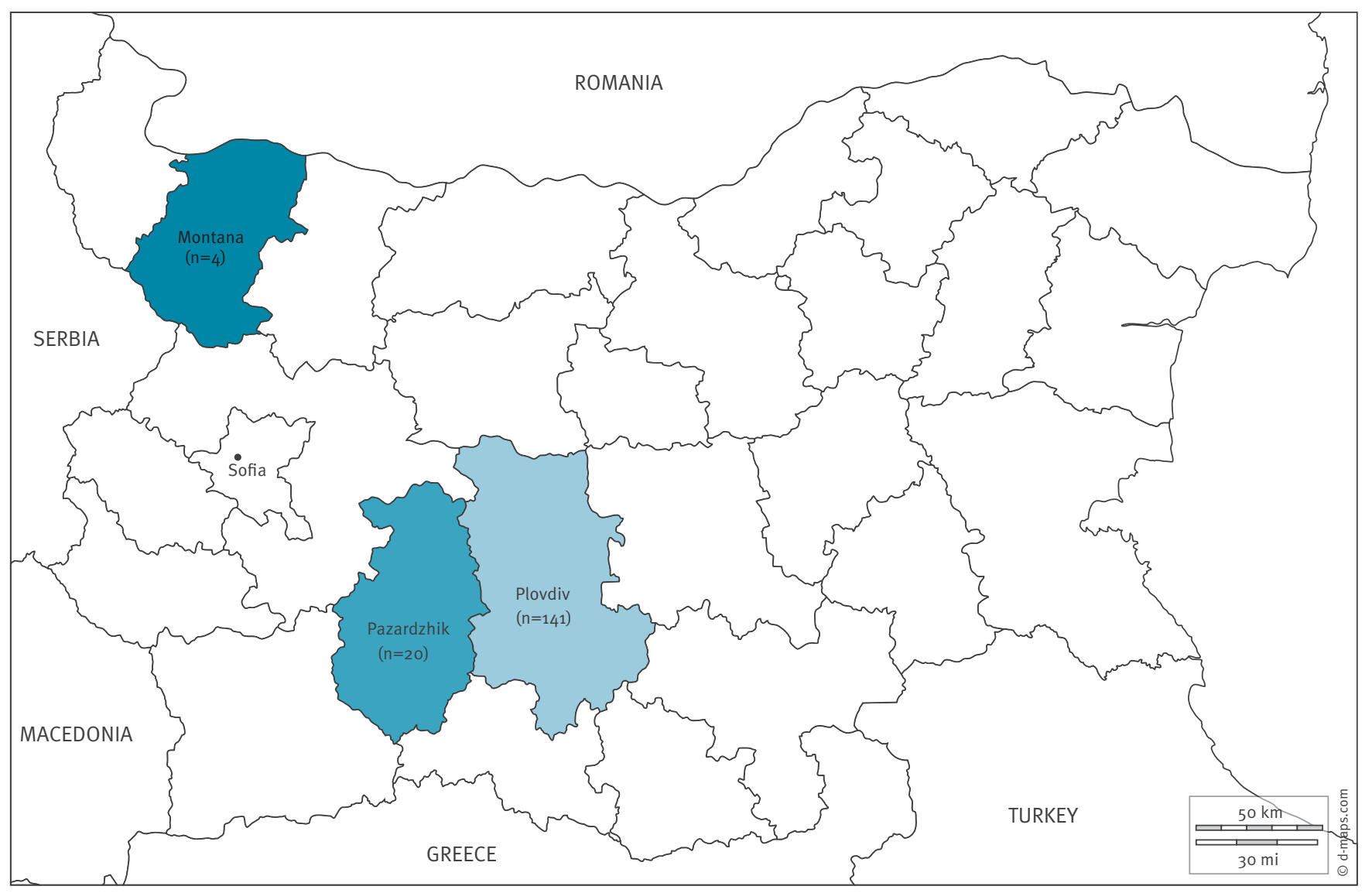

Map obtained from d-maps: http://d-maps.com/carte.php?num_car=5666\&lang=en. 


\section{FIGURE 3}

Phylogenetic tree showing the measles genotype B3 in Bulgaria, March to August 2017

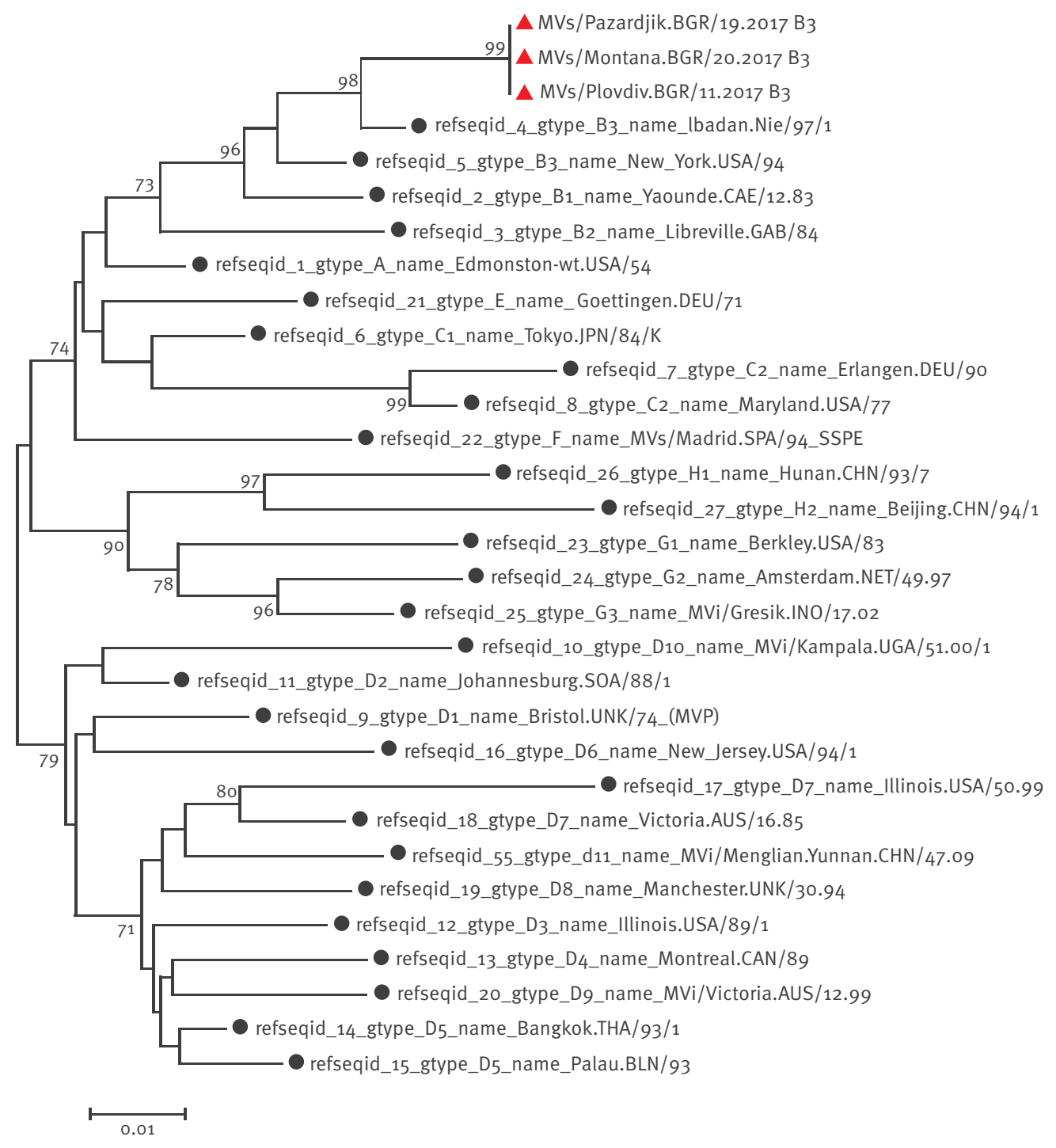

Based on C-terminal 450 nucleotides of the Nucleoprotein (N) gene of the measles virus and World Health Organization reference strains [17]. The phylogenetic tree was generated by MEGA version 5.05 by neighbour-joining method with 1,000 bootstrap replicates; only bootstrap values of $\geq 70$ are shown. Sequences from Bulgaria $(n=3)$ are marked with a red triangles.

Among vaccinated cases, those having received at least one dose of a measles-containing vaccine $(77 ; 47 \%)$ were prevailing. The distribution of measles cases by age groups and vaccination status is shown in Table 1.

Complications were registered in nine cases: two presented with pneumonia and seven with diarrhoea. One of the confirmed measles cases, a child under 1 year of age, died.

Cases were recorded in three of the 28 Bulgarian administrative regions (Figure 2). As in the previous large measles outbreak in Bulgaria (2009-2011), the Roma population living in Plovdiv and Pazardjik was the most affected group $(n=147$ cases, $89 \%)$. The cases described here represent the three clusters from the regions of Plovdiv, Pazardjik, and Montana. The epidemiological link between Plovdiv and Pazardjik clusters is under investigation.

\section{Plovdiv region}

The index case was found here on 17 March 2017. This is the most affected region with $141(85 \%)$ measles cases reported. Among these cases, $100(71 \%)$ are confirmed, 35 (25\%) are probable and six (4\%) are possible cases. Almost all measles cases (127, 90\%) were registered among the Roma community. The median age of cases is 5 years (range: $<1-55$ ).

Pazardjik region

The first case was reported to the NMSS on 13 May 2017, in a child aged 15 months, vaccinated at the 
TABLE 1

Distribution of measles cases by age groups and vaccination status, Bulgaria, March-August $2017(\mathrm{n}=165)$

\begin{tabular}{|l|c|c|c|c|c|c|c|c|}
\hline \multirow{2}{*}{$\begin{array}{l}\text { Vaccination status } \\
\text { (number of doses administered) }\end{array}$} & \multicolumn{9}{c|}{ Age group (years) } \\
\cline { 2 - 10 } & \multicolumn{1}{|c|}{1} & $1-4$ & $5-9$ & $10-14$ & $15-19$ & $20-29$ & $>30$ & Total \\
\hline o & 35 & 20 & 2 & 0 & 0 & 5 & 5 & 67 \\
\hline 1 & 0 & 27 & 21 & 5 & 4 & 2 & 1 & 60 \\
\hline 2 or more & 0 & 0 & 1 & 7 & 7 & 2 & 0 & 17 \\
\hline Unknown & 1 & 0 & 0 & 0 & 2 & 4 & 14 & 21 \\
\hline Total & $\mathbf{3 6}$ & $\mathbf{4 7}$ & $\mathbf{2 4}$ & $\mathbf{1 2}$ & $\mathbf{1 3}$ & $\mathbf{1 3}$ & $\mathbf{2 0}$ & 165 \\
\hline
\end{tabular}

\section{TABLE 2}

Measles-mumps-rubella vaccination coverage at national and sub-national level, Bulgaria, 2012-2016

\begin{tabular}{|l|c|c|c|c|}
\hline Year & $\begin{array}{c}\text { MMR1 coverage } \\
(\%)\end{array}$ & Regions with<90\% coverage / total regions & $\begin{array}{c}\text { MMR2 coverage } \\
(\%)\end{array}$ & Regions with<90\% coverage / total regions \\
\hline $\mathbf{2 0 1 2}$ & 93.7 & $3 / 28$ & 94.0 & $3 / 28$ \\
\hline $\mathbf{2 0 1 3}$ & 95.1 & $5 / 28$ & 93.5 & $4 / 28$ \\
\hline $\mathbf{2 0 1 4}$ & 93.2 & $5 / 28$ & $\mathbf{8 8 . 6}$ & $14 / 28$ \\
\hline $\mathbf{2 0 1 5}$ & 91.5 & $9 / 28$ & $\mathbf{8 6 . 9}$ & $16 / 28$ \\
\hline $\mathbf{2 0 1 6}$ & 92.1 & $9 / 28$ & $\mathbf{8 8 . 3}$ & $15 / 28$ \\
\hline
\end{tabular}

MMR: measles-mumps-rubella.

end of March 2017 with the first dose of the measlesmumps-rubella vaccine (MMR1). A total of 20 cases were reported to the NMSS from this region: 18 confirmed at the NRL-MMR, one probable and one possible. All measles cases in this region were occurred in Roma population with a median age of 2.5 years (range: $<1-21$ ).

\section{Montana region}

The first case was reported on 2 May 2017 in a nonvaccinated adult in their late 205 , who had visited Romania three weeks before symptom onset, where there is a large measles outbreak ongoing with 8,937 cases recorded between 1 January 2016 and 25 August 2017 [5]. The following case occurred in a family member. Another two sporadic cases were also registered in this region. A total of four cases were reported, all of them confirmed at the NRL-MMR.

\section{Laboratory confirmation}

From 17 March to 31 August 2017, a total of 79 measles cases were tested at the NRL-MMR with a commercial indirect enzyme-linked immunosorbent assay (anti-Measles IgM/lgG antibodies, Euroimmun test kit, Luebeck, Germany). All samples collected from measles cases received at the NRL were tested for IgM and IgG antibodies against both measles and rubella. The remaining samples were tested for anti-measles IgM/ IgG antibodies in regional laboratories.
Viral RNA extraction and amplification were performed for 41 urine and 56 nasopharyngeal specimens using QIAGEN kit (QIAGEN GmbH, Hilden, Germany).

Genotyping and phylogenetic analysis were performed at the World Health Organization (WHO) European Regional Reference Laboratory for Measles and Rubella, Robert Koch Institute, Berlin, Germany and at the NCIPD in Sofia. Sequential analysis of the samples of the initial cases in Plovdiv, Pazardjik and Montana showed measles genotype B3, which has been dominantly circulating in Europe (France, Italy and Romania) over the past 2 years (Figure 3).

\section{Control measures}

Following the risk assessment of the situation related to increasing measles incidence in many European countries and a permanent threat of importation [6], the Bulgarian Ministry of Health $(\mathrm{MoH})$ disseminated an official warning letter to all Regional Health Inspectorates (RHI) on 13 March 2017.

A National Coordination Council for the management and response to the measles outbreak was established ad hoc at the MoH on 22 March 2017, after the detection of the outbreak. Letters with recommended control measures were provided immediately: general practitioners were requested to check the immunisation status of all persons aged between 13 months and 18 years and to immunise all those unvaccinated with one dose of MMR vaccine; medical specialists in 
hospitals and outpatient settings were requested to be alert to the early detection, timely reporting, isolation, diagnosis, and treatment of measles cases. It was also recommended to hospitalise patients with measles living in crowded households, in order to ensure better conditions for treatment and care and to minimise the spread of the disease in communities with poor living conditions. Therefore, most of the cases in the affected regions were admitted to the infectious diseases ward (159, 96\%).

\section{Vaccination coverage in Bulgaria}

The measles monovalent vaccine was introduced in Bulgaria in 1969. Consecutively, the combined MMR vaccine was implemented for the first dose given at 13 months of age (in 1993) and the second dose at 12 years (in 2001). The analysis of the past 5 years reveals that vaccination coverage with the two doses of MMR is sub-optimal (<95\%) (Table 2). A downward trend of the MMR vaccine coverage, mostly expressed for the second MMR dose, has been observed. During the past 3 years, the national average was below $90 \%$. Subnational analysis shows that one third of the regions have reported an MMR1 coverage below $90 \%$.

\section{Discussion}

Following the occurrence of the index case in March 2017 , three clusters of measles cases were registered in Bulgaria. Roma population living in two neighbouring regions in Plovdiv and Pazardjik was the most affected group.

According to the latest national census in Bulgaria in 2011 [7], the population consists of Bulgarians (84.8\%), Turks (8.8\%) and Roma (4.9\%). Roma inhabit all regions of the country. They live in overcrowded communities often under poor sanitary conditions and they are characterised by frequent travel within the country and abroad [8].

Two main features of the ongoing outbreak can be outlined: (i) the existence of a vulnerable group of Roma population non-immunised or insufficiently immunised and (ii) nosocomial measles transmission in the paediatric departments of two hospitals in Plovdiv. The recommendation to hospitalise vulnerable Roma children, may also have contributed to the latter.

The analysis of the immunisation status of the cases shows a prevalence of those having received at least one dose of a measles-containing vaccine (77; 47\%) however, some of them might have been immunised during their incubation period and thus, these data need to be interpreted with caution.

The last indigenous measles cases in the country before the outbreak in 2009-2011 were registered in 2001. Since then, several importations were reported $[9,10]$. The measles case that occurred in 2009 was followed by a nationwide outbreak with 24,364 cases (cumulative incidence for April 2009-December 2011:
$326 / 100,000$ inhabitants) and a resurgence of endemic measles in the country [11]. Along with the sub-optimal national vaccination coverage with two doses of MMR vaccine registered during the past 5 years, the current outbreak revealed that pockets of non-immunised and insufficiently immunised population, especially in Roma communities, continue to exist.

The low vaccination coverage is a risk factor for importation and spread of measles in Bulgaria. Continued strengthening of surveillance and improving vaccination coverage in general population is need to avoid the spread of the outbreak to other regions of the country and to prevent exportation. The current outbreak also shows that special intensified vaccination activities should be directed to the Roma population.

Measles outbreaks affecting vulnerable groups, including Roma communities, have been reported in other European countries [12-16].

\section{Acknowledgements}

The authors wish to thank all colleagues from the Regional Health Inspectorates in Plovdiv, Pazardjik and Montana for the epidemiological investigation of measles cases and uploading the data to the web-based National Measles Surveillance System.

The authors wish to express their special thanks to Prof. Dr Annette Mankertz and Dr Sabine Santibanez from the WHO European Regional Reference Laboratory for Measles and Rubella, Robert Koch-Institut, Berlin, Germany, for genotyping the measles virus.

Special thanks go also to all medical professionals who have assisted the control measures and treatment.

\section{Conflict of interest}

None declared.

\section{Authors' contributions}

Anna Kurchatova, Stefka Krumova and Nadezhda Vladimirova contributed to data collection, case information and data analysis.

Stefka Krumova, Lubomira Nikolaeva-Glomb and Asya Stoyanova performed laboratory testing of measles samples.

Anna Kurchatova, Nadezhda Vladimirova and Stefka Krumova drafted the manuscript, with the contribution by Lubomira Nikolaeva-Glomb.

Nina Gatcheva, Todor Kantardjiev and Lubomira NikolaevaGlomb were involved in revising the manuscript.

Nina Gatcheva provided final revising the manuscript.

All authors reviewed and approved the final version. 


\section{References}

1. Verbeff PE. [Measles]. In: Verbeff PE, ed. [Special epidemiology]. Sofia: Medicina \& Fiscultura, 1957:237-252. Bulgarian.

2. European Commission. Commission Implementing Decision of 8 August 2012 amending Decision 2002/253/EC laying down case definitions for reporting communicable diseases to the Community network under Decision No 2119/98/EC of the European Parliament and of the Council. Luxembourg: Publications Office of the European Union. L262 Sep 27, 2012. Available from: http://eur-lex.europa.eu/legal-content/EN/TXT /?uri=0J\%3AL\%3A2012\%3A262\%3ATOC

3. Ministry of Health of Bulgaria. [Ordinance 21/18.07.2005 on the procedure for registration, notification and reporting of communicable diseases]. State Gazette. 2005; 62. Bulgarian. Available from: http://lex.bg/en/laws/ldoc/2135508238

4. World Health Organization Regional Office for Europe (WHO/ Europe). 4th Meeting of the European Regional Verification Commission for Measles and Rubella Elimination (RVC) (2015). Copenhagen: WHO/Europe; 2015. Available from: http:// www.euro.who.int/en/health-topics/communicable-diseases/ measles-and-rubella/publications/2016/4th-meeting-of-theeuropean-regional-verification-commission-for-measles-andrubella-elimination-rvc

5. European Centre for Disease Prevention and Control (ECDC). Communicable Diseases Threats Report. Week 35, 27 August-2 September 2017. Stockholm: ECDC; Available from: https:// ecdc.europa.eu/sites/portal/files/documents/Communicabledisease-threats-report-2-sep-2017.pdf

6. World Health Organization Regional Office for Europe (WHO/ Europe). Measles outbreaks across Europe threaten progress towards elimination. Copenhagen: WHO/Europe; 28 Mar 2017. Available from: http://www.euro.who.int/en/media-centre/ sections/press-releases/2017/measles-outbreaks-acrosseurope-threaten-progress-towards-elimination

7. National Statistical Institute. Final results from census in Bulgaria, 2011. Sofia: National Statistical Institute; [Accessed 6 Jul 2017]. Bulgarian. Available from: http://www.nsi.bg/ census2011/pagebg2.php?p2 $=175 \&$ sp2 $=190$

8. Rechel B, Blackburn CM, Spencer NJ, Rechel B. Access to health care for Roma children in Central and Eastern Europe: findings from a qualitative study in Bulgaria.Int J Equity Health. 2009;8(1):24. DOI: 10.1186/1475-9276-8-24 PMID: 19566936

9. Gatcheva N, Mihneva Z, Mehandjieva V, Petkova V. The fever-rash surveillance revealed no indigenous transmission following the importations in 2005 and 2006.Problems of Infectious and Parasitic Diseases.2007;35(2):30-3.

10. Marinova L, Ivanova S. Measles among non-immune population under risk in the country, 2013.12th Congress on clinical microbiology and infection, Sofia, 12-14 Apr 2014. Bulgarian.

11. Muscat M, Marinova L, Mankertz A, Gatcheva N, Mihneva Z, Santibanez S, et al. The measles outbreak in Bulgaria, 2009-2011: An epidemiological assessment and lessons learnt. Euro Surveill. 2016;21(9):30152. DOI: 10.2807/1560-7917. ES.2016.21.9.30152 PMID: 26967661

12. Grammens T, Schirvel C, Leenen S, Shodu N, Hutse V, Mendes da Costa E, et al. Ongoing measles outbreak in Wallonia, Belgium, December 2016 to March 2017: characteristics and challenges. Euro Surveill. 2017;22(17):30524. DOI: 10.2807/1560-7917.ES.2017.22.17.30524 PMID: 28488998

13. Filia A, Amendola A, Faccini M, Del Manso M, Senatore S, Bianchi S, et al. Outbreak of a new measles $B_{3}$ variant in the Roma/Sinti population with transmission in the nosocomial setting, Italy, November 2015 to April 2016. Euro Surveill. 2016;21(20):30235. DOI: 10.2807/1560-7917. ES.2016.21.20.30235 PMID: 27240004

14. George F, Valente J, Augusto GF, Silva AJ, Pereira N, Fernandes T, et al. Measles outbreak after 12 years without endemic transmission, Portugal, February to May 2017. Euro Surveill. 2017;22(23):30548. DOI: 10.2807/1560-7917. ES.2017.22.23.30548 PMID: 28661392

15. European Centre for Disease Prevention and Control (ECDC). Communicable Disease Threats Report. Week 27, 2-8 July 2017. Stockholm: ECDC; Available from: https://ecdc.europa.eu/ sites/portal/files/documents/Communicable-disease-threatsreport-08-jul-2017.pdf

16. Rogalska J, Santibanez S, Mankertz A, Makowka A, Szenborn L, Stefanoff P. Spotlight on measles 2010: An epidemiological overview of measles outbreaks in Poland in relation to the measles elimination goal.Euro Surveill. 2010;15(17):19549. PMID: 20460084

17. World Health Organization (WHO). Measles Nucleotide Surveillance (MeaNS) Database. London: Public Health England. [Accessed: Jun 2017]. Available from: http://www. who-measles.org/Public/Web_Front/main.php

\section{License and copyright}

This is an open-access article distributed under the terms of the Creative Commons Attribution (CC BY 4.0) Licence. You may share and adapt the material, but must give appropriate credit to the source, provide a link to the licence, and indicate if changes were made.

This article is copyright of the authors, 2017. 